S'exprimer autrement: poétique et enjeux de l'allégorie à l'âge classique, Marie-Christine PIOFFET, AnneÉlisabeth SPICA

\title{
Laura Rescia
}

\section{(2) OpenEdition}

\section{Journals}

\section{Edizione digitale}

URL: https://journals.openedition.org/studifrancesi/11455

DOI: 10.4000/studifrancesi. 11455

ISSN: 2427-5856

\section{Editore}

Rosenberg \& Sellier

\section{Edizione cartacea}

Data di pubblicazione: 1 avril 2018

Paginazione: 126

ISSN: 0039-2944

\section{Notizia bibliografica digitale}

Laura Rescia, «S'exprimer autrement: poétique et enjeux de l'allégorie à l'âge classique, Marie-Christine PIOFFET, Anne-Élisabeth sPICA», Studi Francesi [Online], 184 (LXII | I) | 2018, online dal 02 juillet 2018, consultato il 15 novembre 2021. URL: http://journals.openedition.org/studifrancesi/11455 ; DOI: https://doi.org/10.4000/studifrancesi. 11455

Questo documento è stato generato automaticamente il 15 novembre 2021.

\section{(c) (i) (2) $\Theta$}

Studi Francesi è distribuita con Licenza Creative Commons Attribuzione - Non commerciale - Non opere derivate 4.0 Internazionale. 


\title{
S'exprimer autrement: poétique et enjeux de l'allégorie à l'âge classique, Marie-Christine PIOFFET, Anne- Élisabeth SPICA
}

\author{
Laura Rescia
}

\section{NOTIZIA}

S'exprimer autrement: poétique et enjeux de l'allégorie à l'âge classique, Marie-Christine PIOFFET, Anne-Élisabeth SPICA (éd.), XIII ${ }^{e}$ colloque du Centre International de Rencontres sur le $17^{\mathrm{e}}$ siècle, Université York, Toronto, 8-10 mai 2014, Tübingen, Narr Francke Attempto Verlag, 2016, $301 \mathrm{pp}$.

Elemento fondamentale nella storia del pensiero occidentale, l'allegoria nel xviI secolo si sviluppa trasversalmente, attraversando la retorica, la pittura e la filosofia, nella sua accezione di discorso metaforico, attraverso il quale l'ingegno dell'artista può far mostra di sé. Il gran numero di opere di riferimento pubblicate a partire dalla fine del XVI secolo testimonia dell'importanza di questa modalità ideativa ed espressiva all'epoca di nostro interesse: dall'Iconologia di Cesare Ripa, diffusa notoriamente in Francia nella traduzione di Jean Baudoin, che si occuperà anche della versione francese delle favole di Esopo Frigio, alle numerose traduzioni e adattamenti dei Geroglifici di Orapollo; nel campo delle opere di edificazione religiosa, basterà ricordare la Philosophie des images del gesuita Ménestrier e i Symboles de la Bible del giansenista Fontaine. Figura dell'ornatus, legata al preziosismo, l'allegoria suscita l'interesse dei letterati e dei frequentatori dei salons mondani: riferendosi ai sudditi di Louis XIV, Georges Couton ha parlato di génération allégorisante. L'interesse della tematica è indubbio, e la numerosità e varietà delle comunicazioni, presentate al convegno del CIR 17 tenutosi a Toronto nel 
2014, poi raccolte in questo volume, ne è la prova. I diciotto contributi sono articolati in quattro sezioni.

2 Nella prima, dopo un importante articolo introduttivo dedicato alla definizione e precisazione della nozione (A.-E. SPICA, L'allégorie, «figure et image», pp. 3-27), sono raggruppati gli interventi dedicati all'iconologia, nel cui ambito l'allegoria appare quale efficace mezzo di inventio e di dialogo, nella sua configurazione visiva o discorsiva (E. FAURE-CARRICABURU, La domination de l'allégorie en peinture: les ambivalences d'un mode de représentation transgénérique, pp. 29-48; S. TONOLO, L'allégorie, en image et en texte, dans les almanachs d'époque Louis XIV conservés à la Bibliothèque de l'Institut de France (1645-1690), pp. 49-63; C. MC CALL PROBES, «Vita Virtutis Expers Morte Peior»: le fonctionnement de l'allégorie dans l'emblématique chez J.B. Chassignet et J.J Boissard, pp. 65-74). La seconda sezione è interamente dedicata alla favola e alla mitologia, campi di elezione della lettura allegorica. Che si tratti di riconfigurazione mitologica o favolistica, gli interventi sottolineano l'alterna funzione, simbolica o retorica, della parola allegorica (A. GAILlARD, Fable et allégorie à la fin du XVII siècle ou "comment on doit suppléer au manquement du sujet» (Poussin), pp. 77-89; C. BOHNERT, Mythologiae/Mythologie: l'allégorie fabuleuse selon Natale Conti e Jean Baudoin, pp. 91-104; S. PETRELLA, Jean Baudoin et la réception des mythographies au XVII siècle, pp. 105-122; M.A. CROFT, "Ésope à la Cour" (1701) d'Edme Boursault: allégories et clefs historiques, pp. 123-133). Quattro studi sono raggruppati nella terza parte, dedicata all'allegoria nei sermoni, nella narrazione morale e nell'interpretazione biblica, dove essa si dispiega nel discorso dell'enigma e della rivelazione divina (M. VERNET, «Les humbles, pour qui je besogne (...)»: comment J.P. Camus expose la conception post-tridentine de l'allégorie, pp. 137-149; C.-O. STIKER-MÉTRAL, L'amour propre: de l'allégorie à la réflexion morale, pp. 151-161; G. DECLERCQ, "Théâtre est un palais voûté». Un cas d'écriture allégorique chez Racine: le récit de Thésée aux Enfers, pp. 163-184; R. ZAISER, Le sacré et le profane de l'allégorie biblique dans "Esther" de Racine, pp. 185-195). Infine, la quarta sezione raccoglie i contributi relativi alla messa in scena allegorica dell'Io e dell'Altro, nei diversi ritratti di Louis XIV, nelle mazarinades, nelle histoires comiques e nella narrativa burlesca, come nei racconti della colonizzazione americana, tra elogio e condanna; qui l'allegoria è funzionale alla scoperta progressiva dei sensi impliciti, spesso celati perfino nei discorsi ufficiali (F. ASSAF, Louis XIV, sa propre allégorie?, pp. 199-214; P. RONZEAUD, Usages polémiques de l'allégorie en contexte pamphlétaire: les Mazarinades, pp. 215-226; F. POULET, Sens littéral et sens caché dans les histoires comiques de Charles Sorel: pour une allégorèse méthodique et critique, pp. 227-239; J. LECLERC, L'allégorie à l'épreuve de la raison et du ridicule: l'exemple des œuvres burlesques des frères Perrault, pp. 241-252; M. MARRACHE-GOURAUD, La plume des Amériques en son histoire allégorique, pp. 253-270; А. МОТЈ⿰冫, De l'allégorie ethnographique à l'ethnographie allégorique: le cas de l'Amérique, pp. 271-301).

3 Le curatrici, al termine della loro introduzione, corredata da una bibliografia molto sintetica - dovuta forse allo scrupolo di non ripetere elementi bibliografici presenti nei singoli contributi -, auspicano la pubblicazione di un'opera di sintesi sull'allegoria nel Seicento: ci associamo a tale auspicio, sperando costituisca in realtà l'annuncio di una prossima pubblicazione. 